\title{
Natural hazards and technological risk in Russia: the relation assessment
}

\author{
E. Petrova \\ Faculty of Geography, Research Laboratory of Snow Avalanches and Debris-flow, Lomonosov Moscow State University, \\ Moscow, Russia
}

Received: 27 September 2004 - Revised: 17 May 2005 - Accepted: 02 June 2005 - Published: 13 July 2005

Part of Special Issue "Multidisciplinary approaches in natural hazard and risk assessment"

\begin{abstract}
Almost every natural disaster is accompanied by some sort of technological one. A number of studies also show a correlation between technological disasters and various global processes such as solar disturbances, geophysical field variation etc. In this study we attempted to ascertain and codify the relationship between different types of technological disasters and natural hazards. Two types of natural hazards were found, based on their genesis, distribution in time, and impact pattern on the technosphere. Solar and geomagnetic disturbances generally affect technological risk through the failure of automatic machinery and the reduction of operator reliability. They increase the probability of transport accidents, fires, and catastrophic toxic emissions. These types of technological disasters are widely prevalent throughout Russia and in all federal regions. Geological, climatic, hydrological, and other natural hazardous processes increase technological risk through direct mechanical impacts. Their occurrence in space and time depends on the character of the natural process and the specific regional environment. The total number and proportion of technological disasters in federal regions results mainly from the concentration of industrial units and their type, as well as the local natural and social environment. Temporal changes in the number of technological disasters of different groups depend on the prevailing type of natural processes.
\end{abstract}

\section{Introduction}

In the last few decades social, economic and environmental losses caused by technological accidents and calamities have increased all over the world. In Russia more than 1000 people die every year, on average, from technological disasters, while the number of people affected is three times higher (Russian Ministry of Emergencies, 1994-2004). Between 1990 and 2003, more than 90 per cent of the total number

Correspondence to: E. Petrova

(epgeo@mail.ru) of fatalities in Russia were a result of technological disasters, the remainder being attributed to natural ones. Radiation and transport accidents, dangerous chemical and biological emissions, explosions and fires, hydrodynamic and power plant accidents, and damage of treatment plants were the most dangerous.

We regard a technological (natural) disaster as a disturbance of the current activity of a populated region due to abrupt technological (natural) impacts (catastrophes or accidents) resulting in social, economic, and (or) ecological damage, which requires special management efforts for its elimination. Russian statistics regard disasters as phenomena causing four or more fatalities, and (or) injuring 10-15 people, and (or) damaging more than 500000 rubles (EUR $15000)$. The same criteria were used for this study.

The Russian Ministry of Emergencies has published an annual State Report since 1993, reporting the number of technological and natural disasters occurring in Russia and its main administrative units (federal regions). According to official statistical data the greatest number of technological disasters (1174) occurring in Russia happened in 1997. The number decreased to 518 in 2003, before increasing again to 863 in 2004 (Russian Ministry of Emergencies, 1994-2005) (Fig. 1). From 1993-2004, the data shows an average of 877 technological disasters per annum. As shown in Fig. 1 the number of technological disasters is about three times higher than the number of the natural ones and their temporal changes do not coincide with each other.

The majority of researchers dealing with technological risk state that both temporal and spatial distributions of technological disasters are not random but obey certain laws, and that natural factors play essential roles in addition to technical, social, and economic causes (Epov, 1994; Miagkov, 1995). For example, Epov (1994) concludes that the technosphere "depends on its internal laws, which are related with the global system, the Space and the Earth, rather than on operating staff behaviour". He expected environmental impact on the technosphere to result from geodynamics (deformations of the Earth's crust in a wide spectrum of time 


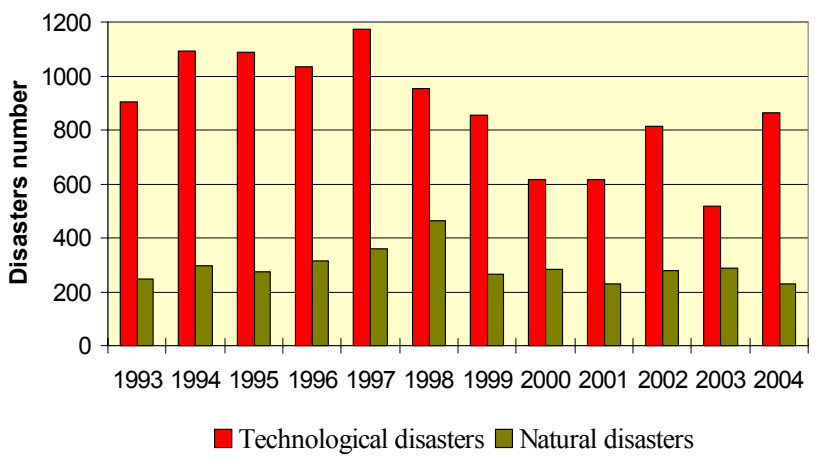

Fig. 1. Temporal changes of technological and natural disasters in Russia.

parameters), flood tides (mutual gravitational influence of the Sun, the Moon, and other planets), geophysical and astrophysical field variations, etc. The total impact of the various combinations of these agents determine the temporal and spatial peculiarities of the technosphere, the regime changes for functioning of its' units, resulting in increasing hazard of accidents and catastrophes. Miagkov (1995) emphasized the significant influence of magnetic storms on the probability of technological disasters.

Hazards researchers and emergency practitioners realize that almost every natural disaster is accompanied by some sort of technological disaster (e.g., hazardous material spills, fuel ruptures, or electrical exposure) (Colorado Department of Public Safety, 1991) capable of radically aggravating any situation. Such technological disasters precipitated by natural disasters are known as natural-technological or "na-tech" events (Young et al., 2002). These events can result from direct destruction of a certain technical object by a natural process (such as destruction of an atomic power plant or chemical plant due to earthquake, landslide, etc.). They can be also the subjects of the secondary effects of natural disasters, with actual or potential threats to the environment, resulting from the accidental release of oils, chemicals and other hazardous or polluting substances (Bishop, 2000). Both cases deal, primarily, with the mechanical impact of natural hazards on the technosphere.

Some other studies found certain correlations between technological disasters and various global processes, which are not usually considered as natural disasters. Epov (1994) found a correlation between solar activity (a Wolf number with reversed sign) and temporal distribution of air crashes as well as fires at storage facilities (Fig. 2). The correlation coefficient is 0.74 . He expected electromagnetic disturbances to be responsible for impacts on electronic devices, electric power units, and chemical processes, causing self-ignition. Desiatov et al. (1972) studied the relationship between solar activity and the number of automobile accidents. According to their data the number of automobile accidents multiplies by four on the second day after a solar flare in comparison with "inactive" solar days. Werner from Hamburg and Reiter from Munich have received similar results from analyses of a

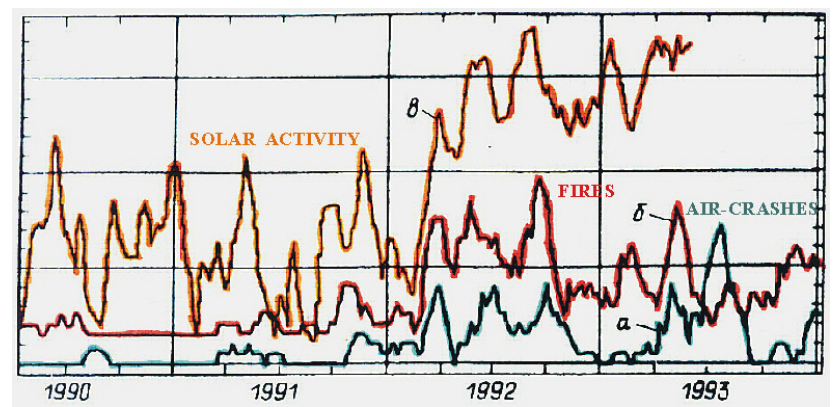

Fig. 2. Temporal correlation between air crashes, fires and solar activity (A.Epov).

great quantity of data (about 100000 automobile accidents). They proved a sharp increase in the number of automobile accidents on the second day after a solar flare. In 1954-1955 Reiter registered that on "active" solar days human response to a signal takes four times longer than a normal response (cited in: Desiatov et al., 1972). Desiatov et al. (1972) and Miagkov (1995) also found that the number of severe mental depression episodes and suicides multiplied by four or five after a solar flare. Therefore, solar flares could affect operators, drivers and pilots. IZMIRAN (The Institute of Terrestrial Magnetism, Ionosphere and Radio Wave Propagation of The Russian Academy of Science) research found a relationship between disturbances of the geomagnetic field and the failure of automated railway machinery (Kanonidi et al., 2002). Anan'in and Merzlyi (2002) mentioned field disturbances, which were regarded as earthquake prognostics, and impulsive emanations of active fault areas among the reasons for air crashes.

With regard to the research mentioned above, we attempted to ascertain a relationship between different types of technological disasters and natural hazards. Unlike the previously cited authors, who only dealt with separate types of technological disasters, we took into account all the possible types of technological disasters in Russia. Thus, for the first time we have quantitatively estimated temporal and spatial distributions for a wide spectrum of technological disasters in Russia.

\section{Research region and methods}

The Russian Federation (RF) was the region of research. We made estimations both for the total RF, in order to analyze temporal regularities, and for its main administrative units (federal regions), in order to trace regional differences. The level of the federal regions was taken for the research because comparable statistical data for the administrative level are available for assessment. These units correspond to states in the USA and federal lands in Germany. The RF consists of 89 federal regions, including republics (such as Karelia, Komi, and the Republic of Dagestan), territories (such as Krasnodar Territory, Krasnoiarsk Territory, and Primorskii Territory), oblasts (such as Moskovskaia Oblast', 
and Leningradskaia Oblast') and autonomous areas (such as Khanti-Mansisk Autonomous Area and Evenki Autonomous Area). The two largest Russian cities, Moscow and Saint Petersburg, are separate federal regions too. Official statistical data in Russia are published for these 89 units of the highest administrative level.

The data were processed with multidimensional statistic methods: R-modification of factor analysis based on the method of principal components. Factor analysis is directed to revealing the minimal number of hypothetic unmeasured variables (factors) necessary for the description of correlated variables between all numerical characteristics (a number of disasters of different types in this case). According to results of the computational analysis it is possible to choose parameters (among the suggested ones) with maximal variance of values and find out groups of parameters, which correlate with each other, thus reducing the number of the parameters for the following analysis (Devis, 1977).

Firstly, we made a factor analysis of 13 parameters for the whole Russia. The total number of natural disasters, the total number of technological disasters, and the number of every 11 types of technological disasters between 1992 and 2001 were taken as parameters for this analysis. Official State Reports of the Russian Ministry of Emergencies were used as input data (Russian Ministry of Emergencies, 1993-2002).

A factor analysis of 15 parameters for the federal regions of the RF was then made. The values of every 15 types of technological disasters for each federal region during the whole observation period between 1992 and 1997 were taken as parameters for assessment. This time period was used because comparable statistical data were available on this administrative level only for this period. At the same time, the initial data allowed us to include a wider range of technological disaster type in comparison with the first analysis (for the whole of Russia) into the analysis. Daily reports of the Russian Ministry of Emergencies about technological emergencies were taken as initial data for the tests.

\section{Results}

Factor analysis of a number of natural and technological disasters in Russia between 1992 and 2001 revealed two groups of disasters with similar temporal distributions during the observation period (Fig. 3). The first group includes fires, air crashes, as well as automobile and railway accidents. Fires have a more closely correlation score to railway accidents (the correlation coefficient is 0.76 ), while air crashes have a more closely correlation to automobile accidents (0.51). According to Epov and other authors cited above, these events have a relation to solar and geomagnetic activity. Evidently, these very processes influence accidents with toxic emissions (or potential dangers of such emissions), which also belong to the first group. This type of disaster most closely correlates in its temporal distribution to fires and technological disasters in general (the correlation coefficient is 0.86 in both cases). The correlation between technological disasters of

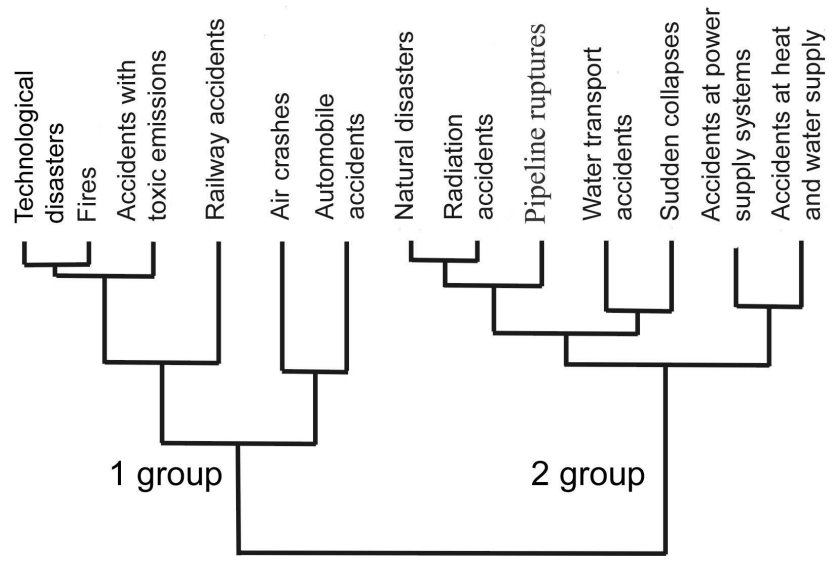

Fig. 3. Groups of disasters with similar temporal distributions.

the first group and solar and geomagnetic activity does not necessarily signify that solar flares and geomagnetic disturbances are the sole reasons for the appearance of all technological disasters of this group. Nevertheless, their correlation might point to the possibility of increasing the total number of one event when increasing the number of the others. Of course, separate technological disasters can also occur without these natural phenomena. However, solar flares and geomagnetic disturbances can increase their probability, influencing the technosphere directly or indirectly. The possibility of such influences should be taken into account.

Technological disasters of the second group (Fig. 3) correlate with the total number of natural disasters. The correlation coefficient for various accidents is found below:

- Radio-active emissions (or potential danger of such emissions) $=0.92$,

- Water transport accidents $=0.83$,

- Pipeline ruptures $=0.80$,

- Power supply systems $=0.76$,

- Sudden collapses of constructions and mines $=0.73$,

- Water and heat supply systems $=0.67$.

The correlations found allow us to suggest a relationship between the named types of technological disasters and natural disasters producing mechanical impact on the technosphere.

Technological disasters of the first group prevail in Russia, accounting for two-thirds of their total amount (Fig. 4). In the diagram they are shown with warm colours. The majority of them are fires (more than 40 per cent). Transport accidents, mainly automobile accidents (10 per cent) take second rank. The number of accidents with toxic emissions comprises 5 per cent. Accidents at water, power, and heat supply systems belong to the second group and comprise about 15 per cent of the total; finally pipeline ruptures account for 7 per cent. 


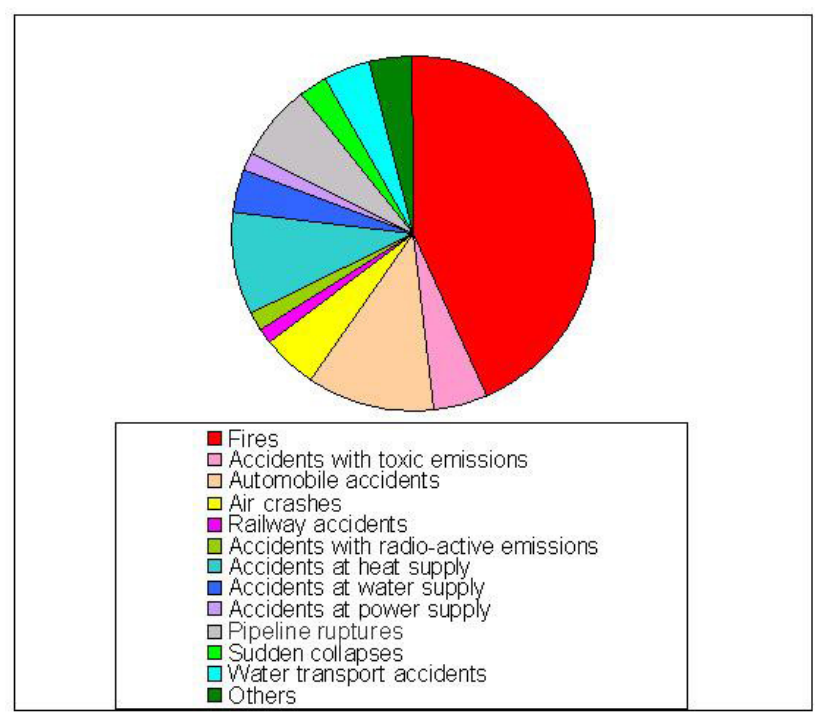

Fig. 4. Proportion of technological disasters in Russia.

Taking into account the reported results we divided natural hazards into two types according to their impact on the technosphere and their effects on increasing technological risk (Fig. 5). The first type of natural hazards includes globalscale solar disturbances and geophysical field anomalies affecting discrete areas. These phenomena can influence the technosphere directly, causing electronic system failure and automatic machinery failure, as well as indirectly, through the decreased reliability of operators, drivers or pilots; thus causing a "human factor". In their turn these failures and the "human error" can cause technological disasters (such as air crashes, automobile and railway accidents etc.).

Geological, climatic, hydrological, and other natural hazards belong to the second type. Causing mechanical impacts they thus become triggers for technological and naturaltechnological disasters. This type of natural hazard includes earthquakes, volcanic eruptions, landslides, avalanches, hurricanes, cyclones and tornadoes, hailstones, lightning, windstorms, snow and ice storms, temperature extremes, epidemics, wild fires, floods, drought, etc. The physical manifestations of this type vary greatly by their spatial scale and geographical location. For example, according to the University of Colorado studies, earthquakes are the most common cause of natural-technological disasters (na-techs) in the USA (73 per cent). Hurricanes create 8 per cent of na-techs, floods 5 per cent, lightning, winds, storms, wild fires, landslides, fogs and others comprise the remainder (Showalter, Myers, 1992). However, the majority of na-techs in Russia are caused by floods, windstorms, heavy snowfalls, and extremely low temperatures during winter.

The regions of Russia undoubtedly differ from each other, in both the number and the proportion of technological disasters. Most of the technological disasters (both by absolute number and per area unit) take place in the Central and Northwestern economic regions. We tried to find regularities

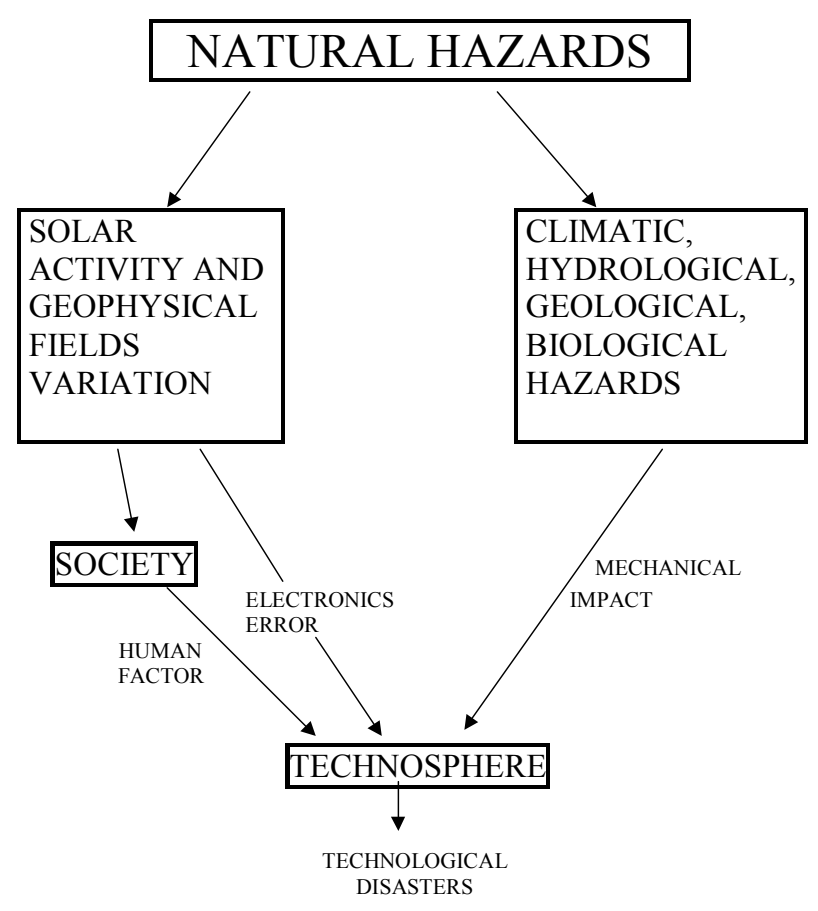

Fig. 5. Types of natural hazards with different impact on technosphere.

in the spatial distribution of technological disasters occurring in Russia by taking into account the quantity of disasters of the 15 technological types in all the 89 federal regions of the RF between 1992 and 1997. Four groups of technological disasters with similar distributions within the federal regions were detected using factor analysis (Fig. 6, Table 1). Factor loads found in this analysis for each parameter (the values of technological disasters) are shown in the Table 1.

Comparison of Fig. 6 and Fig. 3 shows that some types of technological disasters group together more or less equally in both analyses. In all likelihood, this clustering of various technological disasters, which seem to demonstrate no relation with each other, indicates that their distribution both in time and space is not wholly random but can be connected with influence of the objective factors, regardless of human actions. Thus, air crashes, automobile and railway accidents are in the same group (group 1). Another example is the sudden collapse of constructions and mines, and pipeline ruptures (the second analysis unites them with fires and explosions in mines, the failure of water filtering equipment, as well as fires and explosions at fuel storages, which were not taken in the first analysis) (group 3). As it was shown above in the first case (group 1), the influences of solar and geomagnetic activity and geophysical fields prevail in comparison with other natural causes, whilst in the second case (group 3) the mechanical impact of natural processes could be the main factor. However, transport fires and those in buildings as well as accidents with toxic emissions are included in group 2 . Accidents at water, power, and heat supply systems also belong to this group. Such spatial coincidence of these disaster 
Table 1. Groups of technological disasters with similar distribution within Russian federal regions (according to factor load).

\begin{tabular}{lrrrr}
\hline Technological disasters & 1st factor & 2nd factor & 3rd factor & 4th factor \\
\hline $\mathbf{1}$ group & & & & \\
Air crashes & -0.11 & -0.11 & $\mathbf{- 0 . 7 8}$ & 0.29 \\
Railway accidents & 0.27 & 0.16 & $-\mathbf{0 . 3 1}$ & -0.14 \\
Automobile accidents & 0.02 & 0.23 & $-\mathbf{0 . 5 5}$ & -0.12 \\
Accidents with radio-active emissions & 0.23 & -0.27 & $-\mathbf{0 . 6 2}$ & -0.15 \\
\hline 2 group & & & & \\
Fires in buildings & $\mathbf{0 . 7 7}$ & -0.02 & -0.13 & 0.03 \\
Accidents with toxic emissions & $\mathbf{0 . 8 2}$ & -0.06 & -0.0 & -0.08 \\
Transport fires & $\mathbf{0 . 6 4}$ & 0.09 & -0.2 & 0.14 \\
Accidents at heat supply systems & $\mathbf{0 . 7 4}$ & -0.05 & 0.02 & 0.37 \\
Accidents at power supply systems & $\mathbf{0 . 7 6}$ & -0.03 & 0.13 & 0.03 \\
Accidents at water supply systems & $\mathbf{0 . 4 3}$ & 0.07 & -0.13 & -0.26 \\
\hline 3 group & & & & \\
Fires and explosions in mines & 0.02 & $\mathbf{0 . 8}$ & 0.12 & 0.04 \\
Sudden collapses of constructions and mines & 0.45 & $\mathbf{0 . 5 7}$ & 0.17 & -0.1 \\
Pipeline ruptures & -0.06 & $\mathbf{0 . 2 8}$ & -0.44 & 0.02 \\
Failures of water filtering equipment & -0.15 & $\mathbf{0 . 8 1}$ & -0.08 & 0.12 \\
\hline 4 group & & & & -0.06 \\
Water transport accidents & 0.1 & 0.09 & $\mathbf{0 . 9}$ \\
\hline
\end{tabular}

Bold type in table indicates significant factor loads.

types, which have different temporal distributions, evidently can be explained by the high concentration of infrastructure and population density within industrial regions. In this case this very factor plays the main role in the spatial distribution of these technological disasters. The fourth group consists of water transport accidents, whose distribution depends on the location of water resources.

\section{Discussion and perspectives}

In general, the results of the presented study corroborate the assumptions that technological disasters are not wholly random in their temporal and spatial distributions but obey certain laws. Unlike the previously cited authors, who dealt with separate types of technological disasters and with separate natural hazardous processes only, we took into account all possible types of technological disasters and all possible natural hazards in Russia. Two types of natural hazards have been found according to their genesis, temporal distribution, and their pattern of impact on the technosphere. Using factor analysis two corresponding groups of technological disasters with similar temporal distribution have been revealed.

1. The solar and geomagnetic disturbances can increase technological risk through of the failure of electronic system, automatic machinery and the reduction of operator reliability. Such influences can increase the probability of transport accidents (air crashes, automobile and railway accidents), fires, and catastrophic toxic emissions. These types of technological disasters prevail all



Fig. 6. Groups of technological disasters with similar regional distributions.

over Russia and in all federal regions. It is clear then, that solar flares and geomagnetic disturbances are not the single cause for each technological disaster of this group, however they can increase failure probability and 
the risk of accident. It should be noted, that solar and geomagnetic disturbances are not usually considered as natural disasters.

2. Geological, climatic, hydrological, and some other natural hazardous processes increase the technological risk by direct mechanical impacts on the technosphere. Their occurrence in space and time depends on the character of natural process and the specific regional environment. Such impacts can increase probability of sudden collapses of constructions and mines, pipeline ruptures, water transport accidents, accidents at water, power, and heat supply systems and some other disasters.

Four groups of technological disasters with similar distribution within the federal regions have been revealed using factor analysis. Such spatial coincidence between various technological disasters, which seem to demonstrate no relation with each other, can be connected with influence of the objective factors, regardless of human actions. The total number and proportions of technological disasters in federal regions results mainly from the concentration of industrial units and their type, as well as the local natural and social environment. Temporal changes in the number of technological disasters can depend on the prevailing type of natural processes. It requires special investigation on the local level. The specific pattern of natural disasters in each federal region should be examined.

The statistical methods we applied (as well as statistical methods in general) do not allow us to reveal the precise cause for each technological disaster, since statistics do not examine each individual case. Nevertheless, these methods permit us to ascertain increasing the total number of technological disasters when increasing the number of natural hazardous events. It indicates, that a cause-effect-relationship between them can exist, what requires further investigation. The relationship between various natural disasters and technological disasters should be examined.

The research we carried out does not definitively state that global processes and natural hazards are the sole cause for each separate technological disaster. Without doubt technical, economic and social factors play an essential role in their occurrence; however natural factors can increase the probability of the occurrence technological disasters. Our results permit us to elucidate which technological disasters could be influenced by natural processes of the first (solar and geomagnetic disturbances) or the second type (natural hazards causing direct mechanical impacts). Using our results it is possible to make a prognosis, for example, based on the dynamics of natural processes of the first or the second type in a certain region it is possible to predict the increased risk for the related types of technological disasters and to take the necessary steps to prevent them.

This study is the first attempt of such an analysis for the Russia. We have taken a total number of natural disasters for the research. In future their pattern and a contribution of various types of natural disasters should be investigated.
Acknowledgements. The author would like to express her thanks to Y. Mironov and T. Vashchalova for important remarks, which were very helpful. Special thanks go also to O. Trapeznikova and G. Symons for help in translating this paper into English.

Edited by: T. Glade

Reviewed by: one referee

\section{References}

Anan'in, I. V. and Merzlyi, A. M.: Tectonically active zone of Russian northern areas and their impact on air crashes, Ecology of Russian Northern Areas. Problems, situation forecast, ways of development, decisions, Proceedings of the International Conference, Arkhangelsk, 2, 4-8 (in Russian), 2002.

Bishop, J. A.: Guidelines on Rapid Environmental Assessment for Response in Natural Disasters, Joint UNEP/OCHA Environment Unit. Advisory Group on Environmental Emergencies Fourth Meeting, Brussels, 20-21 November 2000.

Desiatov, V. P., Osipov, A. I., and Suzdal'skaya, O. V.: Solar Activity and Death-Rate Statistics, Solntze, electrichestvo, jzizn' (The Sun, Electricity, Life), Proceedings of Memorial Readings devoted to A. L. Chijevskii, Moscow, 90-92 (in Russian), 1972.

Devis, D.: Statistics and Analysis of Geological Data, Moscow, (in Russian), 1977.

Epov, A. B.: Regularities in Occurrence of Technogenical Emergencies and their Relationship with Natural Processes, Problems of Safety under Emergencies, Moscow, 12, 14-20 (in Russian), 1994.

Young, S. L., Balluz, L., and Malilay, J.: Natural-technological events: Frequency and severity of toxic releases during and after natural disasters, The 130th Annual Meeting of APHA, 9, 44213, http://apha.confex.com/apha/130am/techprogram/paper_ 44213.htm, 2002.

Kanonidi, H. K., Oraevskii, V. N., Belov, A. V., Gaidash, S. P., and Lobkov, V. L.: Railway Automatic System Failures under Geomagnetic Storms, Problems of Emergency Forecasting, Proceedings of a Scientific and Practical Conference, Moscow, 41-42 (in Russian), 2002.

Lessons Learned from Limon: A Tornado After-Action Report, Disaster Preparedness Improvement Grant Program, August, Golden, Division of Disaster Emergency Services, Colorado Department of Public Safety, Colorado, 1991.

Miagkov, S. M.: Geography of Natural Risk, Moscow Univ. Press, Moscow, 224 p. (in Russian), 1995.

Miagkov, S. M. and Kozlov, K. A.: The extent of technogenous and natural hazards in Russia, Herald of the Moscow State Univ., Series 5, Geography, 5, 3-11 (in Russian), 1993.

Petrova, E.: Natural hazards and technological risk: the relation assessment, Geophys. Res. Abstr., Vol. 6, 00895, 2004,

SRef-ID: 1607-7962/gra/EGU04-A-00895.

Showalter, P. S. and Myers, M. F.: Natural Disasters as the Cause of Technological Emergencies: A Review of the Decade 1980-1989, Working Paper \#78, Boulder, Natural Hazards Research and Applications Information Center, Univ. of Colorado, Colorado, http://www.colorado.edu/hazards/wp/wp78/ wp78.html, 1992.

State reports of Russian Ministry of Emergencies about Protecting Population and Territory of Russian Federation against Natural and Technological Disaster in 1993-2004, Emergency Ministry of Russia, Moscow, 1994-2005, in Russian. 